\title{
VII
}

\section{THE INFLUENCE OF PREGNANCY UPON THE COURSE OF SYPHILIS *}

By JAROLD E. KEMP, M.D., Chicago, Illinois, and WILLIAM C. MENNINGER, M.D., Topeka, Kansas.

THE altered course of syphilis in pregnant females, in contrast to that in males, was first noted by Colles ${ }^{1}$ in I837. Following his exposition of what has since been known as Colles' law, the subject of syphilis and pregnancy has aroused the interest of a large number of observers, including Hutchinson, ${ }^{2}$ Fournier, ${ }^{3}$ Diday, ${ }^{4}$ and Ricord, ${ }^{5}$ four of the most prominent syphilologists of the last century. Engaged by the question of the paternal or the maternal transmission of the disease to the fetus, the majority of the earlier observers failed to realise that pregnancy might be held responsible for the different behaviour of syphilis in men than in women. The conflicting opinions which prevailed prior to the discovery of Treponema pallidum and the advent of the Wassermann reaction are probably best presented by the two following quotations from Jonathan Hutchinson ${ }^{2}$ : Speculating upon the validity of Colles' law, and realising that pregnancy might alter the course of early syphilis, he said : "In attempting, however, to realise in imagination what is possible in these directions, I think we may without difficulty perceive that it is possible for the poison to pass over in a mode very different, indeed, from that of chancre-contagion and, therefore, not unlikely to be followed by very different results." Later he felt that ${ }^{6}$ : "It is impossible, in the highest degree, that a large number of married women should acquire syphilis in its primary form, pass through its secondary stages, and yet never know it. . . . In nine cases out of ten, acquired syphilis is an affair which its victim cannot either ignore or forget." In other words, in view of his later experiences, Hutchinson felt that women who had borne syphilitic children, without showing any of the usual

* From the Syphilis Division of the Public Health Institute, Chicago. 


\section{THE INFLUENCE OF PREGNANCY}

manifestations of early syphilis themselves, had in all probability escaped infection.

Following the discovery of Treponema pallidum, Buschke ${ }^{7}$ demonstrated their presence in the inguinal glands, and Uhlenhuth and Mulzer ${ }^{8}$ in the milk, of symptomless mothers who had borne syphilitic children. After the advent of the Wassermann reaction a voluminous literature showed that 90 per cent. of these mothers gave positive tests and were, therefore, syphilitic. Unfortunately, however, a positive blood Wassermann test in pregnant women who showed no clinical evidence of syphilis, was by some observers regarded for a long time as a false positive reaction resulting from the pregnancy. Complete agreement that such women are syphilitic is comparatively recent. ${ }^{9}$

In I920 Brown and Pearce ${ }^{10}$ showed that a group of rabbits inoculated with syphilis at the time of conception reacted less severely than a similarly infected non-pregnant group. A few years later Chesney ${ }^{11}$ showed that syphilis generally ran a milder course in female rabbits than in males. He did not, however, compare pregnant and non-pregnant groups.

In I923, Moore ${ }^{12}$ called attention again to the suppression of the lesions of early syphilis in women who had conceived and become infected simultaneously, and concluded from this fact and from other data that the recent advances in the knowledge of syphilis proved Colles' law invalid. His contention that all women who bear syphilitic children are themselves syphilitic has since been generally accepted. Three years later, in a study of asymptomatic neurosyphilis, he ${ }^{13}$ found that its incidence was three times as frequent among males as among females, and suggested, as a result of his previous study, that this difference might be due to the inhibiting influence of pregnancy upon the course of the syphilitic infection. Keidel ${ }^{14}$ concurred in this assumption, and in later studies Solomon ${ }^{15}$ confirmed Moore's findings. The latter felt, however, that these conclusions could not be accepted without further clinical studies.

Contrary to the conclusions of Moore and Solomon are those of Belote, ${ }^{16}$ who concluded from his experiences that pregnancy did not influence the incidence of neurosyphilis in females. Unfortunately, the value of Belote's material is disguised by his effort to draw a fine differen- 


\section{BRITISH JOURNAL OF VENEREAL DISEASES}

tiation between invasion and involvement of the neuraxis, and his failure to state the time relationship of pregnancy to infection in his cases. In general, his observations confuse rather than clarify the subject. In the discussion of Belote's paper, it was suggested that any difference between his findings and those of Moore might be explained by the larger number of coloured patients in the latter's clinic population. Because of the higher incidence of neurosyphilis among white patients, this is an important consideration, and one of several points that must be clarified before the exact relationship of pregnancy and syphilis can be determined.

The most important and extensive of the studies mentioned above are those of Moore. ${ }^{13}$ However, he considered a group of females as a whole, and did not divide them into those who had become pregnant after they had contracted syphilis and those who had not. The decreased incidence of neurosyphilis in females, in contrast to males, was ascribed to the most prominent difference between the two sexes-the occurrence of pregnancy in the female.

\section{PROBLEM}

In considering some problems of syphilis with regard to the influence of pregnancy, it occurred to us to determine the influence of pregnancy upon the early course of syphilis and the actual incidence of neurosyphilis in groups of syphilitic males, non-pregnant syphilitic females (hereafter referred to as nulliparæ), and females who had experienced one or more pregnancies after contracting the disease (hereafter referred to as multiparæ). If pregnancy is the main factor inhibiting the development of neurosyphilis, then its incidence in the latter group should be much less than in the group of females as a whole, and in the non-pregnant group should approach that found in the males.

\section{Material Studied}

The 767 cases in this study, 400 males and 367 females, are derived from a large syphilis clinic, the clientèle of which is almost entirely white and of a low income group. In their selection, only those patients from whom a 208 


\section{THE INFLUENCE OF PREGNANCY}

reliable history of the time relationships of pregnancy and infection with syphilis* could be obtained, and those who had had an examination of their spinal fluid, or in whom the clinical diagnosis of neurosyphilis was unquestionable, were included. Patients in whom pregnancy was interrupted before the third month, and those with minor pupillary or reflex changes not definitely diagnostic of neurosyphilis and in whom spinal fluid studies were lacking, were excluded. It is apparent, therefore, that our figures probably represent a minimum incidence of neurosyphilis. However, since the majority of the patients came to this clinic because of knowledge or suspicion of the disease, the incidence of neurosyphilis is probably higher than in the average medical clinic where syphilis is frequently discovered accidentally. ${ }^{17}$ This, however, does not alter the validity of the following comparisons.

\section{RESUlts}

\section{Pregnancy and Early Syphilis}

The frequency with which the females of this study gave a history of early syphilis is shown in Table I. ${ }^{18}$

TABLE I.-Frequency of the Diagnosis of Early Syphilis in Multipare and Nullipare

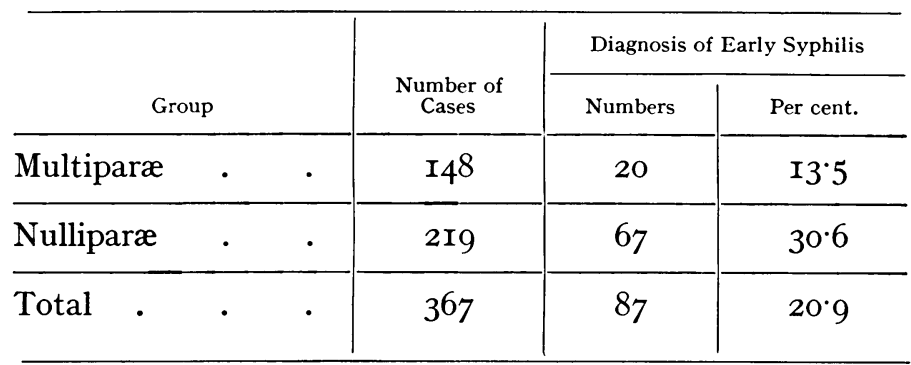

Of the 367 , only 87 , or 23.7 per cent., gave an unquestionable history of primary or secondary syphilis. This is in accord with the experience of others that women with syphilis infrequently give a history of the usual evidences of infection. Of the nulliparæ, 67 , or 30.6 per cent., gave such a history. In contrast, only 20 , or 13.5 per cent.,

* In patients who gave no history of early syphilis, examination of the husband, the results of premarital blood Wassermann tests, the birth of congenitally syphilitic children, etc., enabled us to determine accurately if pregnancy had occurred before or after infection with syphilis. 


\section{BRITISH JOURNAL OF VENEREAL DISEASES}

of the multiparæ were certain of a similar experience. Since we could discover no difference other than pregnancy between these two groups of females, it seems logical to assume that this factor was probably responsible for the suppression of the lesions of early syphilis among the multiparæ.

\section{Pregnancy and Neurosyphilis}

The incidence of neurosyphilis in the groups of males and females is shown as follows :-

400 Males. . . . . . 470 per cent. neurosyphilis. 367 Females

Thus, by including all the females in one group, the 367 cases show an incidence of $3 \mathrm{I} \cdot 6$ per cent., $15 \cdot 4$ per cent. lower than in an equal number of male patients. This difference is in substantial agreement with the findings of others. ${ }^{19}$ However, if we divide the females into pregnant and non-pregnant groups and contrast them with males, we find the following:-

400 Males

2I9 Females, with no history of preg-

nancy following infection with syphilis

I48 Females, with a history of one or more pregnancies after contracting syphilis. $47^{\circ} \circ$ per cent. neurosyphilis.

$34 \%$

$277 \quad "$,

These data reveal that in this series of men neurosyphilis is 12.3 per cent. more frequent than in nonpregnant women, and 19.3 per cent. more frequent than in women with a history of one or more pregnancies following infection with syphilis. Women without a history of pregnancy following the syphilitic infection show a 7 per cent. greater frequency of neurosyphilis than the women who gave a history of one or more pregnancies following the infection.

In I03 multiparæ who had received no treatment during the first three years of the infection, it was possible to determine accurately the duration of syphilis at the time of the first pregnancy. These cases have been divided into three groups as follows : (I) cases in which pregnancy occurred within six months of infection; (2) cases in which pregnancy occurred between the sixth month and third year of infection, and (3) cases in which pregnancy 


\section{THE INFLUENCE OF PREGNANCY}

occurred after the third year of infection. The data for the three groups are presented in Table II.

TABLE II.-Incidence of Neurosyphilis according to Duration of Infection at Time of First Pregnancy.

\begin{tabular}{|c|c|c|}
\hline & $\begin{array}{c}\text { Number of } \\
\text { Cases }\end{array}$ & $\begin{array}{l}\text { Per cent. of } \\
\text { Neurosyphilis }\end{array}$ \\
\hline $\begin{array}{l}\text { Group I.-Pregnancy occurring within } \\
\text { six months after infection }\end{array}$ & 36 & $47^{\circ} 2$ \\
\hline $\begin{array}{l}\text { Group II.-Pregnancy occurring six to } \\
\text { thirty-six months after infection }\end{array}$ & 35 & $\mathrm{I} 7 \cdot 2$ \\
\hline $\begin{array}{l}\text { Group III.-Pregnancy occurring three } \\
\text { years or more after infection }\end{array}$ & 32 & $34 \cdot 3$ \\
\hline Total . & I03 & $33^{\circ} 0$ \\
\hline
\end{tabular}

While the number of cases is too small to permit accurate deductions, the low incidence of neurosyphilis (I7.2 per cent.) among the group of women in whom pregnancy occurred after the sixth month and before the third year of infection is in sharp contrast to its incidence $(47 \cdot 2$ per cent.) in the group in which infection and pregnancy practically coincided and in the group in which pregnancy did not occur until after the third year of infection $(34.3$ per cent.). It is of interest to note, also, that the incidence of neurosphilis in this group of IO3 females (33 per cent.) was practically the same as its incidence in the entire group of 367 females (3I.6 per cent.) ; and its occurrence among the group of females in which pregnancy and infection practically coincided (47 per cent.), the same as its occurrence among the 400 male patients.

\section{Discussion}

The higher incidence of neurosyphilis among the male patients of this study ( 47 per cent.) than among the female patients ( $3 \mathrm{I} \cdot 6$ per cent.) is not an unexpected finding, and, as stated above, is in agreement with the experiences of others. However, that pregnancy was not the only factor responsible for this difference is shown by the lower incidence of neurosyphilis (34.7 per cent.) among 


\section{BRITISH JOURNAL OF VENEREAL DISEASES}

nulliparous females than among the males. The 7 per cent. difference between the pregnant and non-pregnant groups is statistically significant ${ }^{20}$ and represents in this series of cases the influence of pregnancy in the prevention of neurosyphilis in the female. The 12.3 per cent. increased incidence of neurosyphilis in the male in contrast to the non-pregnant female is in accord with the finding of Chesney $\mathbf{1 1}$ that experimental syphilis in female rabbits runs a milder course than in male animals. The reason for the modified course of the disease in the females is not yet apparent.

The high incidence of neurosyphilis $(47 \cdot 2$ per cent.) in the group of women who experienced their first pregnancy within six months after infection is in sharp contrast to its incidence ( 16.2 per cent.) in the group in whom pregnancy did not occur until after the sixth month and before the third year of infection, and to its incidence $(34.3$ per cent.) in the group in which pregnancy did not occur until the third year after infection. These findings are not surprising when one remembers the frequency with which pregnancy inhibits the lesions of early syphilis. It appears logical to assume that this suppression of the usual secondary reaction may interfere with the patient's immunologic response to the disease and increases the opportunity for invasion of the nervous system. It seems logical to assume, also, that in order to exert a beneficial effect upon the course of the syphilitic infection, pregnancy would have to occur before the involvement of the neuraxis was well established; and that after actual tissue damage had occurred in the nervous system, pregnancy could not exert a beneficial effect.

We realise that this group of cases is probably too small to permit accurate deductions ; however, they generally confirm the findings of Moore, ${ }^{12}$ who noted that late neurosyphilis was an infrequent complication in females who had experienced pregnancy during the first year of their infection with syphilis. The difficulty of securing information of the exact relationship of pregnancy to infection from records which were completed without the amanuensis having this point particularly in mind, is obvious. The difference in the incidence of neurosyphilis between these three groups of females is sufficiently great to suggest the value of additional studies similar to the present one. 


\section{THE INFLUENCE OF PREGNANCY}

\section{SUMMARY}

In a study of 400 males and 367 females about whom all the essential data as to the relationship of pregnancy to infection with syphilis were known, it was found that :

(I) The incidence of neurosyphilis in males was 47 per cent. in contrast to $3 \mathrm{I} \cdot 6$ per cent. in females.

(2) In women who had experienced one or more pregnancies after infection, the incidence of neurosyphilis was 27.7 per cent. in contrast to 34.7 per cent. in those who had never been pregnant.

(3) The incidence of neurosyphilis in I03 untreated patients with syphilis of at least three years' duration, in which the duration of the infection at the time of the first pregnancy could be accurately determined, was $47 \cdot 2$ per cent. in those in whom infection and impregnation practically coincided, in contrast to an incidence of $17 \cdot 2$ per cent. in those in whom pregnancy occurred between the sixth month and the third year of the infection, and an incidence of 34.3 per cent. when pregnancy did not occur until after the third year of infection.

(4) Thirty and six-tenths per cent. of nulliparæ gave an unquestionable history of early syphilis, while only I3.5 per cent. of multiparæ were certain of a similar experience.

\section{CoNCLUSIONS}

This study suggests that while pregnancy may alter the course of early syphilis, it is not the only factor responsible for the decreased incidence of neurosyphilis in females in contrast to males. On the contrary, it suggests that the incidence of neurosyphilis may be increased in women in whom impregnation coincides with or occurs within a short time after infection. It appears also that pregnancy does not influence the incidence of neurosyphilis when it occurs after invasion of the neuraxis is established.

\section{BIBLIOGRAPHY}

(I) Colles, A.: " Practical Observations on the Venereal Diseases and on the Use of Mercury," London, I837.

(2) Hutchinson, J. : “' On Colles' Law and on the Communication of Syphilis from the Fœtus to its Mother," Med. Times and Gaz., 2, p. 643,1876 . 


\section{BRITISH JOURNAL OF VENEREAL DISEASES}

(3) Fournier, A. : “ Du traitement préventif de l'hérédité syphilitique paternelle au cours de la grossesse," Semaine méd., 18, p. 48I I898.

(4) Diday, P.: "A Treatise on Syphilis in New-Born Children and Infants at the Breast," New York, William Wood \& Company, I883.

(5) RICORD, P. : "A Treatise on the Venereal Disease," Philadelphia, Blanchard and Lea, I853.

(6) Hutchinson, J.: "Syphilis," London, Cassell \& Co., I899, pp. 67-68.

(7) Buschke, A., and Fischer, W. : "Ueber die Beziehungen der Spirochaete pallida zur kongenitalen Syphilis," Arch.f. Dermat. u. Syph., 82, p. 63, I906.

(8) Uhlenhuth, P., and Mulzer, P.: "Ueber die Infektiosität von Milch syphilitischer Frauen, Deutsche med. Wchnschr., 39, p. 879, I9I3.

(9) Dinerman, I. A. : “Pregnancy and Early Syphilis," Med. Rec., 143, p. 299, April Ist, I936.

(Io) Brown, W. H., and Pearce, L. : " On the Reaction of Pregnant and Lactating Females to Inoculation with Treponema pallidum.-A Preliminary Note," Am. J. Syph., 4, p. 593, I920.

(II) Chesney, A. M. : " The Influence of the Factors of Sex, Age, and Method of Inoculation upon the Course of Experimental Syphilis in the Rabbit," J. Exp. Med., 38, p. 627, I923.

(I2) Moore, J. E.: "Studies on the Influence of Pregnancy in Syphilis. I. The Course of Syphilitic Infection in Pregnant Women," Bull. Johns Hopkins Hosp., 34, p. 89, I923.

(I3) Moore, J. E.: "Studies in Asymptomatic Neurosyphilis. III. The Apparent Influence of Pregnancy on the Incidence of Neurosyphilis in Women," Arch. Int. Med., 30, p. 548, I922.

(I4) KeIDEL, A. : "Studies in Asymptomatic Neurosyphilis. IV. The Apparent Role of Immunity in the Genesis of Neurosyphilis," J.A.M.A., '79, p. 874, 1922 .

(I5) Solomon, H. C.: " Pregnancy as a Factor in the Prevention of Neurosyphilis," Am. J. Syph., 10, p. 96, r926.

(I6) Belote, G. H. : "Pregnancy and Neurosyphilis," J.A.M.A., 89, p. $268,1927$.

(I7) KeIDEL, A., and Moore, J. E.: "The Wassermann Reaction in the Johns Hopkins Hospital," Bull. Johns Hopkins Hosp., 34, p. I6, I923.

(I8) Menninger, W. C., and Kemp, J. E. : "The Incidence of the Clinical Types of Syphilis in Males, in Pregnant and Non-pregnant Females," Ann. Int. Med., 9, p. I76, I935.

(I9) Moore, J. E. : “The Modern Treatment of Syphilis," Baltimore, Charles C. Thomas, I933.

(20) Rosahn, P. D. : " Statistical Methods for the Laboratory and Clinical Investigator. The Chi-Square Test of Homogeneity," J. Lab. and Clin. Med. In press. 